\title{
PENGARUH KUALITAS PELAYANAN JASA DAN HARGA TERHADAP LOYALITAS PELANGGAN PADA HOTEL PERMATA LAND RANTAUPRAPAT
}

\author{
Ali Sahputra Dalimunthe \\ Dosen Tetap Sekolah Tinggi Ilmu Ekonomi (STIE) Labuhanbatu
}

\begin{abstract}
ABSTRAK
Loyalitas Pelanggan adalah komitmen pelanggan terhadap layanan, layanan atau pemasok terdaftar (Perusahaan), berdasarkan sikap yang sangat positif dan tercermin dalam pembelian ulang yang konsisten. Loyalitas Pelanggan dapat dipengaruhi oleh banyak faktor termasuk kualitas layanan dan harga. Objek penelitian ini adalah Permata Land Rantauprapat Hotel.. Populasi dalam penelitian ini adalah konsumen yang menginap di Hotel Permata Land Rantauprapat. Sampel dalam penelitian ini adalah 98 responden. Metode pengumpulan data menggunakan kuesioner. Teknik analisis yang digunakan adalah regresi berganda. Hasil analisis regresi antara kualitas layanan til loyalitas pelanggan mendapatkan hasil positif dari 0035 hkd dan dari hasil pengujian hipotesis Menggunakan uji - t menunjukkan hasil sejumlah besar 10.532 dan up. 0,003 <a=0,05. Hasil analisis regresi berganda antara harga kepuasan konsumen mendapatkan hasil positif dari 0734 dan dari hasil pengujian hipotesis Menggunakan uji t menunjukkan hasil sejumlah besar 11.583 dan up. $0.000<a=0,05$. Dette kan kualitas konkluderede att layanan dan harga memiliki dampak positif dan signifikan terhadap loyalitas pelanggan.
\end{abstract}

Kata kunci: Kualitas Layanan, Harga, Loyalitas Pelanggan.

\section{PENDAHULUAN}

Perubahan paradigma baru dalam pengelolaan sebuah hotel adalah merubah visi ke arah pelayanan yang baik pada pelanggan. Persaingan antar Hotel dalam industri hotel nampaknya semakin meningkat, sehingga manajemen sebuah hotel harus di evaluasi kembali. Pengelolaan Hotel mestinya di ikuti dengan panawaran pelayanan yang simpatik bagi para pengguna jasa hotel harus terus ditingkatkan. Juga tidak kalah penting adalah fasilitas, harga dan kemungkinan promosi dari pengelolaan hotel mendapat perhatian yang memadai.

Keberhasilan sebuah bisnis perhotelan dalam meraih kepuasan pengguna jasanya pada tahap awal ditentukan antara lain oleh keunggulan produknya, oleh karena sebagian besar produknya berupa jasa maka keberhasilan itu hanya dapat dipertahankan dan dikembangkan oleh sikap manusianya yang disebut sikap melaksanakan serviceexcellence (pelayanan unggul) kepada parapelanggan di Hotel tersebut. Telah terbukti di negaranegara maju bahwa untuk memuaskan para pelanggan dapat dilakukan melalui service excellence.Service excellence yaitu bagaimana carapara karyawan atau sumberdaya manusia pada institusi tersebut melayani para pelanggan sehingga mereka mempunyai kesan yang positif terhadap institusi tersebut (Fandy Tjiptono, 2011:146). Service excellence identik dengan sikapbaik atau behavior dalam 
memandu layanan. Akibatnya para pelanggan akan merasa puas dan terus menggunakan jasa hotel tersebut, tetapi yang lebih penting lagi yaitu penyampaian dari mulut ke mulut mengenai service excellence suatu bisnis hotel atau institusi itu dan sebagai akibatnya volume jasa layanan atau usaha lembaga tersebut akan meningkat. Hotel Permata Land merupakan hotel baru berbintang tiga di Rantauprapat, Sumatera Utara. Hotel Permata Land Rantauprapat adalah hotel yang mengutamakan kenyamanan, penataan, serta, pelayanan terbaik untuk Anda dan keluarga atau partner bisnis Anda. Hotel Permata Land Rantauprapat menyediakan ruangan untuk acara seminar, pelatihan, gathering, pameran, ulang tahun, dan arisan. Hotel yang beralamatkan di Jl.Ahmad Yani No.133 Rantauprapat Kab.Labuhan Batu, Sumatera Utara memiliki berbagai fasilitas sebagai beikut:

Tabel 1.

Jenis Fasilitas pada Hotel Permata Land Rantauprapat

\begin{tabular}{|l|l|l|}
\hline Ruangan & Kapasitas & Harga \\
\hline B.J Sinurat Hall & $300-350$ pax & Rp. 4.000.000,- \\
\hline Olive Room & $150-200$ pax & Rp.3.000.000,-- \\
\hline Yosefin Room & $100-150$ pax & Rp.2.000.000,-- \\
\hline Blandina Room I & $50-100$ pax & Rp.1.500.000,- \\
\hline Blandina Room II & $25-50$ pax & Rp.1.250.000,-- \\
\hline Martha Room & $25 \quad-50$ pax & Rp.1.250.000,-- \\
\hline $\begin{array}{l}\text { Karaoke Keluarga } \\
\text { Large Room (A) } \\
\text { Medium Room (B) } \\
\text { Small Room (C) }\end{array}$ & $\begin{array}{l}7-12 \text { orang } \\
5-10 \text { orang } \\
2-7 \text { orang }\end{array}$ & $\begin{array}{l}\text { Rp.150.000/jam } \\
\text { Rp.130.000/jam } \\
\text { Rp.110.000/jam }\end{array}$ \\
\hline
\end{tabular}

Sumber: Hotel Permata Land Rantauprapat, 2017 layanan hotel lain yang disediakan yaitu VIP Lounge, CCTV dan keamanan 24-jam, free wi-fi di area hotel, free accessswimming pool, taman rekreasi, accept credit card, layanan gratis reservasi tiketkereta / travel, dan loundry.

Tuntutan para pelanggan jasa hotel yang terus meningkat ini menciptakan suatu kondisi dimana kualitas jasa dan harga yang ditawarkan kepada pengguna jasa dituntut untuk menjadi yang terbaik. Karena dengan demikian keluhan pengguna jasa dapat dieliminir. Sebagai contoh dapat dilihat pada fasilitas hotel disamping peningkatan fasilitas penunjang. Fasilitas ini dijadikan keunggulan suatu hotel terhadap hotel lain. 


\begin{tabular}{|l|l|}
\hline Tipe kamar & Harga Normal \\
\hline Standard & Rp. $242.000,-$ \\
\hline Superior & Rp. $314.600,-$ \\
\hline Deluxe & Rp. $405.350,-$ \\
\hline VIP & Rp. $484.000,-$ \\
\hline Suit I & Rp. $665.500,-$ \\
\hline Suit II & Rp. $565.500,-$ \\
\hline Family & Rp. $907.500,-$ \\
\hline Economy & Rp. $125.000,-$ \\
\hline Extra Bed & Rp. $102.850,-$ \\
\hline
\end{tabular}

Sumber: Hotel Permata Land Rantauprapat, 2017

Berdasarkan tabel diatas dapat dilihat berbagai tipe kamar yang disediakan oleh Hotel Permata Land Rantauprapat. Fasilitas kamar yang dapat disediakan oleh Hotel Permata Land Rantauprapat yaitu comfortable double /Twin / Single Bed, TV LED plus multi chanel satelite, perlengkapan mandiseperti air panas, individual AC control, 2 botol air mineral dan free wi-fi.

Tabel 3.

Frekuensi menggunakan jasa hotel dalam 6 bulan terakhir

\begin{tabular}{|l|l|l|}
\hline Frekuensi & Frekuensi & Persentase \\
\hline$\leq 5$ kali & 54 & 54 \\
\hline $6-10$ kali & 24 & 24 \\
\hline $11-15$ & 13 & 13 \\
\hline$\geq 16$ kali & 9 & 9 \\
\hline Total & 100 & 100 \\
\hline
\end{tabular}

Sumber data diolah, 2017

Berdasarkan tabel diatas dapat dilihat bahwa mayoritas pelanggan dalam 6 bulan terakhir menggunakan jasa hotel sebanyak 5 kali atau kurang dari 5 kali yaitu 54 pelanggan atau 54\%, sebanyak 24 responden atau 24\% dalam 6 bulan terakhir menggunakan jasa hotel antara 6-10 kali, sebanyak 13 responden atau $13 \%$ dalam 6 bulan terakhir menggunakan jasa hotel antara 11-15 kali, dan sebanyak 9 responden atau $9 \%$ dalam 6 bulan terakhir menggunakan jasa hotel lebih dari 16 kali.

Dengan adanya fenomena semacam ini, maka peningkatan pelayanan tidak lagi akan bertumpu pada produk dan fasilitas yang dimiliki oleh suatu hotel, melainkan terletak pada pelayanan (service) yang diberikan. Dengan adanya perkembangan tingkat kritis dalam memilih hotel 
yang semakin baik akan membuat pengguna jasa menjadi lebih kritis dan makin pintar membandingkan pelayanan suatu hotel dengan hotel lainnya dan berpikir jangka panjang dalam menggunakan jasa hotel. Demikian juga dengan harga dan lokasi hotel, ini juga merupakan indikator. Harga yang bersaing dan lokasi yang strategis tempaknya sebagai alternatif pemilihan para pengguna jasa hotel sebagai tempat persinggahannya. Pentingnya faktor pelayanan memang sudah tidak dapat ditawar lagi oleh industri hotel, karena pelayanan kepada para pengguna menjadi dasar dari bisnis ini dimana merupakan bisnis pelayanan (service). Atas dasar latar belakang tersebut maka penelitian tentang pengaruhnya indikator atau atribut yang relevan bagi loyalitas konsumen pada sebuah hotel, maka penulis melakukan penelitian dengan judul : "Pengaruh kualitas pelayanan jasa dan harga terhadap loyalitas pelanggan pada Hotel Permata Land Rantauprapat".

\section{Rumusan Masalah}

Berdasarkan dari latar belakang masalah di atas, maka rumusan masalah dalam penelitian ini adalah:

Apakah terdapat pengaruh antara kualitas pelayanan jasa terhadap loyalitas pelanggan pada Hotel Permata Land Rantauprapat?

Apakah terdapat pengaruh antara harga terhadap loyalitas pelanggan pada

Hotel Permata Land Rantauprapat?

Apakah terdapat pengaruh antara kualitas pelayanan jasa dan harga loyalitas pelanggan pada Hotel Permata Land Rantauprapat?

\section{TINJAUAN PUSTAKA Kualitas Pelayanan Jasa}

Kualitas produk menurut Kotler (2008) adalah kemampuan produk untuk menjalankan fungsinya yang mencakup daya tahan, keandalan, kekuatan, kemudahan penggunaan dan reparasi produk serta ciri - ciri bernilai lainnya. Kualitas memberikan suatu dorongan kepada pelanggan untuk menjalin ikatan hubungan yang kuat dengan perusahaan. Dalam jangka panjang ikatan seperti ini memungkinkan perusahaan untuk memahami dengan seksama harapan pelanggan serta kebutuhan mereka. Menurut Sinaga, (2010:30), kunci pembeda pada produk jasa dan barang adalah pada kenyataan bahwa konsumen seringkali menerima nilai dari jasa tanpa mendapatkan kepemilikan permanen dari elemen yang berwujud.

Menurut Mahanani, (2010:28), definisi kualitas jasa adalah ukuran sejauh mana suatu pelayanan yang diberikan dapat memenuhi harapan pelanggan. Kualitas pelayanan jasa menurut Tjiptono (2011), adalah tingkat keunggulan yang diharapkan dan pengendalian atas tingkat keunggulan tersebut untuk memenuhi keinginan pelanggan. Dengan kata lain, ada dua faktor utama mempengaruhi kualitas jasa, yaitu expected service dan perceived service atau kualitas jasa yangdiharapkan dan kualitas jasa yang diterima atau dirasakan.

\section{Harga}

Sedangkan Engel (2006)mendefinisikan harga sebagai sejumlah uang (ditambah beberapa produk) yang dibutuhkan untuk mendapatkan sejumlah kombinasi dari produk dan pelayanan. 
Penetapan harga merupakan hal yang paling krusial dan sulitdiantara unsur-unsurbauran pemasaran kotler(2008:519)mengemukakan bahwa :

"Harga merupakan satu satunya elemen bauran pemasaran yang menghasilkan pendapatan, elemenelemen lainya menimbulkan biaya".

Menurut Fuad (2006)harga adalah sejumlah kompensasi (uang maupun barang, kalau munkin) yang dibutuhkan untuk mendapatkan sejumlah kombinasi barang atau jasa. Dalam pengertian lain, Laksana (2008)menyatakan bahwa "Harga adalah jumlah uang (kemungkinan ditambah beberapa uang) yang dibutuhkan untuk memperoleh beberapa kombinasi sebuah produk dan pelayanan yang menyertainya" Menurut Kotler (2008)“Harga adalah jumlah uang yan ditagihkan untuk suatu produk atau jasa".

Sedangkan menurut Kotler dan Amstrong(2008:345), harga adalah sejumlah uang yang ditagihkan atas suatu produk dan jasa atau jumlah dari nilai yang ditukarkan para pelanggan untuk memperoleh manfaat dari memiliki ataumenggunakan suatu produk atau jasa.

\section{Loyalitas Pelanggan}

Tjiptono (2011) menyatakan bahwa loyalitas pelanggan adalah komitmen pelanggan terhadap suatu merek, jasa atau pemasok (perusahaan), berdasarkan sikap yang sangat positif dan tercermin dalam pembelian ulang yang konsisten.

MenurutWahyuNugroho (2005:11) loyalitas pelanggan didefinisikan sebagai suatu ukuran kesetiaan dari pelanggan dalam menggunakan suatu merek produk atau merek jasa pada kurun waktu tertentu pada situasi dimana banyak pilihan produk ataupun jasa yang dapat memenuhi kebutuhannya dan pelanggan memiliki kemampuan mendapatkannya. Loyalitas menggambarkan keinginan pelanggan untuk terus berlangganan dalam jangka waktu yang panjang, melakukan pembelian, menggunakan produk atau jasa secara berulang dan merekomendasikan perusahaan terhadap kolega atau orang lain.

\section{METODE PENELITIAN}

Populasi adalah wilayah generalisasi yang terdiri atas objek atau subjek yang mempunyai kualitas dan karakteristik tertentu yang ditetapkan oleh peneliti untuk dipelajari kemudian ditarik kesimpulannya. (Sugiono, 2007:90). Populasi dalam penelitian ini adalah masyarakat yang berkunjung ke Hotel Permata Land Rantauprapat. Sampel adalah bagian dari jumlah dan karakteristik yang dimilikiolehpopulasi. (Sugiono, 2007:91).

Penentuan jumlah sampel ditentukan dengan menggunakanbeberapametodeantara lain denganmenggunakanrumussebagaiberikut Widiyanto (2008).

Moe : Margin of Error, yaitu tingkat kesalahan maksimal yang dapat ditoreransi, ditentukan sebesar $10 \%$

Dari hasil perhitungan sampel diatas maka jumlah sampel dalam penelitian ini sebanyak 98 responden.

\section{Teknik Pengumpulan Data}

Metode pengumpulan datadan informasi yang diperlukan dalam penelitian ini, penulius menggunakan metode sebagai berikut: a. Wawancara (Interview) 
Yaitu dilakukan dengan cara tanya jawab langsung dengan masyarakat maupun karyawan Hotel Permata Land Rantauprapat.

\section{b. Angket (questioner)}

Yaitu metode yang digunakan untuk mendapatkan data dengan cara membuat daftar pertanyaan - pertanyaan yang secara sistematis dengan tujuan mendapatkan data yang diinginkan. Pertanyaan dalam kuisioner dibuat berdasarkan skala likert dengan alternative jawaban yaitu: sangat setuju,setuju, netral, tidak setuju, dan sangat tidak setuju. Kemudian data kualitatif yang sudah diangkatkan tersebut diolah dengan teknis analisis.

\section{Jenis dan Sumber Data}

Adapun jenis sumber data yang penulis perlukan dalam penelitian ini adalah: a.

Data primer

Data primer adalah data yang diambil langsung dari tempat dimana penelitian dilakukan berupa wawancara kepada pimpinan dan karyawan perusahaan serta jawaban responden terhadap kuisioner yang berhubungan dengan penelitian. b. Data sekunder

Data sekunder adalah data yang diperoleh dalam bentuk data yang sudah tersedia yang di peroleh dari Hotel Permata Land Rantauprapat seperti gambaran umum Hotel, dan struktur organisasi.

\section{HASIL DAN PEMBAHASAN Uji Validitas}

Uji validitas menggunakan tiga puluh $(\mathrm{n}=98)$ responden sebagai sampel ujicoba. Perhitungan uji validitas ini menggunakan Bivariate Pearson dengankriteria bahwadata akan valid jika nilai $r$ hitung lebih dari $r$ tabel $(0,176)$

\section{Tabel 4. Hasil Uji Validitas Iklan}

\begin{tabular}{|l|l|l|l|l|}
\hline Dimensi & Indikator & $\begin{array}{l}\mathrm{R} \\
\text { hitung }\end{array}$ & $\begin{array}{l}\mathrm{R} \\
\text { tabel }\end{array}$ & Kesimpulan \\
\hline \multirow{4}{*}{$\begin{array}{l}\text { Kualitas } \\
\text { pelayanan }\end{array}$} & Item 1 & 0,811 & 0,176 & Valid \\
\cline { 2 - 5 } & Item 2 & 0,799 & 0,176 & Valid \\
\cline { 2 - 5 } & Item 3 & 0,807 & 0,176 & Valid \\
\cline { 2 - 5 } & Item 4 & 0,801 & 0,176 & Valid \\
\cline { 2 - 5 } & Item 5 & 0,805 & 0,176 & Valid \\
& & & & \\
\hline
\end{tabular}

Berdasarkan hasil uji validitas penelitian pada tabel di atas, dapat dilihat bahwa semua item dinyatakan valid, artinya telah memenuhi kriteria yaitu $r$ hitung lebih $r$ tabel $(r$ tabel $=0,176)$. 


\section{Uji Reliabilitas}

Setelah melakukan validitas, maka selanjutnya adalah melakukan uji reliabilitas dengan teknik Uji Cronbach's Alpha dengan kriteria nilai Cronbach 'sAlpha lebih dari 0,60.' 
Tabel 7. Hasil Uji Reliabilitas

\begin{tabular}{|l|l|l|l|}
\hline Indikator & $\begin{array}{l}\text { Cronbach's } \\
\text { Alpha }\end{array}$ & Nilai kritis & Kesimpulan \\
\hline Kualitaspelayanan & 0,712 & 0,6 & Reliabel \\
\hline Harga & 0,755 & 0,6 & Reliabel \\
\hline Loyalitas pelanggan & 0,802 & 0,6 & Reliabel \\
\hline
\end{tabular}


Berdasarkan hasil uji realibilitas yang telah dilakukan untuk semua variabel, maka dapat disimpulkan bahwa ketiga variabel tersebut dinyatakan reliabel karena nilai Cronbach's Alpha melebihi 0,6.

\section{Uji Hipotesis}

\section{H1: kualitas pelayanan berpengaruh terhadap loyalitas pelanggan}

Hasil pengujian hipotesis pertama dengan t hitung sebesar 10.532 dan t tabel sebesar 1,988 , karena $\mathrm{t}$ hitung > t tabel $(10.532>1,988)$ maka terdapat berpengaruh yang signifikan antara kualitas pelayanan terhadap loyalitas pelanggan. Hal ini menunjukkan bahwa semakin baik kualitas pelayanan maka semakin tinggi loyalitas pelanggan.

\section{H2: Harga berpengaruh terhadap loyalitas pelanggan}

Hasil pengujian hipotesis kedua dengan thitung sebesar 11.583 dan t tabel sebesar 1,988, karena $\mathrm{t}$ hitung $>\mathrm{t}$ tabel $(11.583>1,988)$ maka terdapat berpengaruh yang signifikan antara harga terhadap loyalitas pelanggan. Hal ini menunjukkan bahwa semakin baik harga maka semakin tinggi loyalitas pelanggan.

H3: kualitas pelayanan dan harga berpengaruh terhadap loyalitas pelanggan Hasil pengujian hipotesis ketiga dengan $\mathrm{F}$ hitung sebesar 67.082 dan $\mathrm{F}$ tabel sebesar 2.70, karena $\mathrm{F}$ hitung $>\mathrm{F}$ tabel $(67.082>2.70)$ maka secara bersamasama kualitas pelayanan dan harga berpengaruh signifikan terhadap loyalitas pelanggan. Diintepretasikan bahwa semakin baik kualitas pelayanan dan harga maka semakin tinggi loyalitas pelanggan.

\section{DAFTAR PUSTAKA}

Arikunto, Suharsimi. 2007. Manajemen penelitian. Jakarta : Rineka Cipta.

Dahlan Muhadi, Djamudin, (2013). Analisis pengaruh kualitas layanan jasa dan penetapan harga terhadap kepuasan dan loyalitas konsumen (Studi Kasus Pada Hotel Grand Cempaka)

Dwi Aryanti dan Febrina Rosinta (2010). Pengaruh Kualitas Layanan terhadap Kepuasan Pelanggan dalam Membentuk Loyalitas Pelanggan

Engel, James F., Roger D. Black well, Paul W. Miniard. 2006. Perilaku Konsumen.

Terjemahan F.X. Budianto. Jakarta : Binarupa Aksara 


\section{Jurnal Ecobisma Vol 2 No. 1 Jan 2017}

Fiks Elinda, Nina ernawati, (2012). Analisis pengaruh faktor kualitas pelayanan dan harga terhadap kepuasan konsumen ( Studi Kasus Pada Hotel Srikandi Bandungan,

Kabupaten Semarang )

Fuad, M, H Christine, Nurlela, Sugiarto,dan Paulus Y.E.F, 2006, Pengantar Bisnis, Erlangga, Jakarta.

Ghozali, Imam. 2006. “Aplikasi Analisis Multivariate Dengan Program SPSS”.Semarang: Badan Penerbit Undip.

Ibnu, Widiyanto, 2008. Pointers : Metodologi Penelitian. Semarang: BP Undip

Kotler, Philip dan Gary Amstrong,2008, Prinsip-PrinsipPemasaran, Jilid 1, EdisiKeduabelas, Erlangga, Jakarta.

Lupiyoadi, Rambat dan Hamdani,2006, Manajemen PemasaranJasa, Salemba Empat, Jakarta.

Laksana,Fajar, 2008, Manajemen Pemasaran,Graha Ilmu, Yogyakarta. 